\title{
A tale of two winds: species richness patterns of reef corals around the Semporna peninsula, Malaysia
}

\author{
Z. Waheed • B. W. Hoeksema
}

Received: 30 March 2012 /Revised: 22 August 2012 /Accepted: 26 September 2012 /Published online: 25 October 2012

(C) The Author(s) 2012. This article is published with open access at Springerlink.com

\begin{abstract}
The highest concentration of Malaysian coral reefs is found in the coastal area of Semporna, eastern Sabah, which is located just within the boundaries of the Coral Triangle, the area of maximum marine species diversity. The Semporna reefs consist of five major geomorphological reef types, which include lagoonal reefs inside a proto-atoll, fringing reefs, continental patch reefs, a barrier reef and a reef capping an oceanic island. Surveys were carried out in this area to compare the species richness patterns of the scleractinian coral families Agariciidae, Euphylliidae, and Fungiidae from nearshore to offshore reefs. In total, 44 species of Fungiidae, 31 Agariciidae and 15 Euphylliidae have been observed, including 12 new records for Sabah and 4 records that are so far considered endemic to northeast Borneo. Based on coral species compositions for each site, multivariate analyses suggest the distinction of two main groups that reflect a difference in reef exposure, with a gradient in increasing coral diversity from the exposed barrier reef to the relatively sheltered nearshore reefs. Some reefs have been damaged by blast fishing, a threat still prevalent in the area. Nevertheless, the high coral species diversity is remarkable, and to date, Semporna holds the record for the highest species richness of Fungiidae, which surpasses records from other areas in the Coral Triangle.
\end{abstract}

Electronic supplementary material The online version of this article (doi:10.1007/s12526-012-0130-7) contains supplementary material, which is available to authorized users.

Z. Waheed $\cdot$ B. W. Hoeksema $(\bowtie)$

Department of Marine Zoology, Naturalis Biodiversity Center, PO Box 9517, 2300 RA Leiden, The Netherlands

e-mail: bert.hoeksema@naturalis.nl

Z. Waheed

Borneo Marine Research Institute, Universiti Malaysia Sabah, Jalan UMS,

88400 Kota Kinabalu, Sabah, Malaysia
Keywords Scleractinia $\cdot$ Agariciidae $\cdot$ Euphylliidae Fungiidae $\cdot$ Coral Triangle $\cdot$ Coral reefs $\cdot$ Species richness $\cdot$ Wind exposure

\section{Introduction}

Species richness of coral reefs is driven by an array of factors including geological history, ecological processes and physical environment (Hoeksema 2007; Veron et al. 2009), of which habitat heterogeneity is paramount (Hoeksema and Moka 1989; Cornell and Karlson 1996; Karlson 1999; Karlson and Cornell 1999). High species diversity of scleractinian corals is usually found in habitats with distinct environmental gradients, such as exposure to wind, wave and terrestrial inputs (Cleary et al. 2005; Hoeksema 2007, 2012a). Several studies on the onshore-offshore species richness patterns of scleractinian corals have been carried out in tropical coral reef systems (Done 1982, 1983; Moll 1983; Moll and Suharsono 1986; Hoeksema 1993, 2012a; Cleary et al. 2005, 2006; Becking et al. 2006; DeVantier et al. 2006; Van der Meij et al. 2010). These studies conclude that different reef systems from onshore to offshore may have distinct coral composition and community structure. In Malaysia, few published studies on scleractinian species richness patterns and coral reefs in general have been conducted (Harborne et al. 2000; Toda et al. 2007). Consequently, in the eastern state of Sabah, the coral fauna is poorly investigated (but see Wood and Tan 1987; Fenner 2001; Ditlev 2003).

Sabah contains more than $75 \%$ of Malaysian reefs (Burke et al. 2002). High concentrations of reefs are found in the Banggi group of islands in the north and in the Semporna islands reef complex in the southeast of Sabah, both of which are within the Coral Triangle (Veron et al. 2009). The first mention of Semporna's corals was in relation to using raised coral limestone as building materials (Fitch 1950; Roe 1951). Later, the presence of coral reefs was reported by Kirk (1962), with a further account in a note 
by Morris (1973). Subsequent studies covered larger areas, and described in detail the physical characteristics of the coral reefs (Morris 1978; Wood 1987), with information on the species diversity and distribution of scleractinian corals (Wood and Tan 1987), macro-invertebrates (George and George 1987), and fish (Wood and Wood 1987) of the Bodgaya Islands and Sipadan Island. Ekspedisi Galaxea'98 reported the status of corals reefs and adjacent ecosystems in Darvel Bay, which is Sabah's largest bay, situated to the north of Semporna (Ditlev et al. 1999). Since then, apart from a few Reef Check surveys that were carried out under the collaboration of Sabah Parks, Marine Conservation Society (MCS) and WWF-Malaysia, the reefs of Semporna and Darvel Bay have remained under-studied, with little published scientific information available (Wood et al. 2004; Wood and Dipper 2008; Ho and Kassem 2009; Affendi et al. 2012).

Wood $(1978,1979,2001)$ indicated that although the reefs of Semporna were among the best in Sabah in terms of reef life diversity, there were signs of threats to the area. In addition to the natural threat of predation by Acanthaster planci (Linnaeus, 1758) (see Morris 1977; Wood 1979), blast fishing has been evident since the late 1970s and continues up to the present (Wood 1978, 1979, 2006a; Wood et al. 2008). Other unsustainable fishing practices in the area include cyanide fishing and muro ami (Pilcher and Cabanban 2000). Tourism, albeit not considered a threat, has caused some pressure on reefs that have been popular diving destinations since the 1980s, such as Sipadan and Mabul. Increasingly, other reefs in the Semporna area are being promoted for dive tourism, including those around Mataking, Pom Pom and all the islands within the Tun Sakaran Marine Park (see Table 1; Fig. 1).

Information on the marine biodiversity of the Semporna region is fragmented because so far only parts of the area have been surveyed in various studies, each using different methods. The area features various geomorphological reef types, including lagoonal reefs inside a proto-atoll, fringing reefs, patch reefs, a barrier reef and a reef capping an oceanic island (Wood 1987, 1994). Together, they represent various different reef environments that may harbour a high diversity of coral reef species, some of which are considered rare or even endemic. Therefore, the area as a whole is suitable to study marine biodiversity patterns from nearshore to offshore reefs in which environmental variables can be taken into account, such as predominant wind direction (see, e.g., Moll 1983; Cleary et al. 2005; Hoeksema 2012a). The purpose of the present study is to discern such diversity patterns for three scleractinian coral families, which were used as proxy for all scleractinian reef coral species. These patterns also include the distributions of rare species, and in particular endemics. Eventually, the results can be applied in planning conservation management strategies involving the use of natural resources relating to subsistence fisheries and dive tourism (see Wood 2001, 2006b).

\section{Materials and methods}

Research area

The barrier reef of the Semporna reef complex lies in the south of the Semporna peninsula and is composed of a chain of small islands and reefs referred to as the Ligitan group of islands and reefs (Wood 1979). The reefs facing the Ligitan Channel in the north are relatively shallow $(<20 \mathrm{~m})$, while those facing the south extend deeper $(>50 \mathrm{~m})$ and are exposed to oceanic elements (Fig. 1). These reefs are not well described with the exception of Sipadan Is. (Wood 1987, 1994; Wood and Tan 1987; Isley et al. 2005) and Mabul Is. (Aw 2009). The oceanic island of Sipadan lies $12 \mathrm{~km}$ south of the barrier reef at the end of the continental shelf and has been proposed as a park. Towards the E-NE of the Semporna peninsula, at the entrance of Darvel Bay, is the Bodgaya reef complex gazetted as the Tun Sakaran Marine Park. There are eight islands in the park of which the two largest are part of a proto-atoll with a lagoon of $25 \mathrm{~m}$ depth (Wood 1987, 2001). Further to the east are several islands with Mataking Is. as the easternmost. The reefs in the N-NW of Semporna are situated in Darvel Bay and are composed of fringing and patch reefs. They are sheltered and characterised by turbid waters with high humic content, especially towards the inner part of the bay (Ditlev 2003).

There are several small rivers near the Semporna peninsula. The Kalumpang and Balung rivers flow southwards into the western part of the barrier reefs, while the Pegagau River flows northwards into the bay, but it is blocked by Pababag Is. Terrigenous input is possibly the cause of the relatively turbid waters on the nearshore reefs in the north and the islands within the bay.

The wet season is during the northeast monsoon that occurs from December to January while the southeast monsoon is during June and July. The transition periods bring variable wind patterns and rainfall (Wood 1994). The outer reefs of Darvel Bay and the Bodgaya reef complex are exposed to the northeast monsoon (Wood 1987; De Silva et al. 1999) and are sheltered from the southwesterly winds by the Semporna peninsula and Bum Bum Is. (Wood 1994). The barrier reefs are exposed to the winds from the south and the east (Wood 1987). Average wind distribution values throughout the year shows that the dominant wind direction is from the S-SE, although the predominant current direction is from north to south and remains moderately constant throughout the year (Wyrtki 1961). The tidal range varies between 1.2 and $2 \mathrm{~m}$ (Wood 1987). 
Table 1 Sites, their proximity to shore or land (Off offshore, Near nearshore), and exposure to wind ( $S$ exposed to the southern winds, $N$ exposed to the northern winds, $I$ intermediate reefs between the latter two, $C$ reefs along the coastline)
No.

No.

Site

Proximity to shore/land

Exposure to wind

Roach Reef, Mid Rock

Off

Off

$\mathrm{S}$

NW Roach Reef, Second Reef

Off

$\mathrm{S}$

SE of Tawau, Hand Rock

Off $S$

SE of Tawau, Darby Rock

Off

Off

Off

SE of Tawau, Alert Patches 3

Erzherzog Reef

Off

Off

Off

S Ligitan Reef, Yoshi Point

Off

Off

Off

Off

Off

Off

Off

Off

Off

Off

Off

Off

Near

Near

Off

Off

Off

Off

Off

Off

Off

Off

Off

Off

Off

Off

Near

Near

Near

Near

Near

Near

Near

Off

Near

Near

Near

Off

Off

Off

$\mathrm{S}$

S

$\mathrm{S}$

S

S

S

$\mathrm{S}$

S

S

S

S

Maiga Is.

Sebangkat Is.

Singamata Pancang

Sibuan Is.

Church Reef 1

Church Reef 2 
Table 1 (continued)

\begin{tabular}{llll}
\hline No. & Site & Proximity to shore/land & Exposure to wind \\
\hline 47 & Larapan Is. & Near & $\mathrm{C}$ \\
48 & Timbun Mata Is. & Near & $\mathrm{N}$ \\
$49 / 49 \mathrm{~b}$ & Balusuan Is. & Off & $\mathrm{N}$ \\
50 & Batik Is. & Near & $\mathrm{N}$ \\
51 & Tabawan Is. & Near & $\mathrm{N}$ \\
52 & Silumpat Is. & Near & $\mathrm{N}$ \\
53 & Batik Kulambu Is. & Near & $\mathrm{N}$ \\
54 & Bakungan Is. & Off & $\mathrm{N}$ \\
55 & Silawa Is. & Near & $\mathrm{C}$ \\
56 & Mata Pahi Is. & Near & $\mathrm{C}$ \\
57 & S Larapan Is. 2 & Near & $\mathrm{C}$ \\
58 & Semporna town, mangrove area & Near & $\mathrm{C}$ \\
59 & Sipadan Is., Baracuda Point & Off & $\mathrm{S}$ \\
60 & Sipadan Is., Hanging Gardens & Off & $\mathrm{S}$ \\
\hline
\end{tabular}

\section{Field sampling}

The research study was carried out during the Semporna Marine Ecological Expedition (SMEE 2010) in Semporna, Sabah $\left(5^{\circ} 57^{\prime}-6^{\circ} 5^{\prime} \mathrm{N}, 115^{\circ} 59^{\prime}-116^{\circ} 5^{\prime} \mathrm{E}\right)$ from 29 November to 18 December 2010. A total of 63 sites (1-40 m depth) were surveyed in a south-north direction, varying from nearshore to offshore reefs that are less than $50 \mathrm{~km}$ from mainland (Fig. 1). The sites were selected based on navigation charts (British Admiralty Charts nos. 1680 and 1681), reconnaissance dives in 2009, and local knowledge on popular tourist dive sites. The selection was designed to cover as much habitat diversity and geographical range as possible.

A species inventory of the coral families Fungiidae, Agariciidae and Euphylliidae was made at each site by employing the roving diver technique (Schmitt et al. 2002; Munro 2005; Hoeksema and Koh 2009). These three families were chosen for this study because they have a wide geographical distribution and are found in various reef habitats. They are also easily distinguishable from other coral families on the reef. All coral specimens were identified according to species concepts presented in taxonomic revisions and coral fauna descriptions: Dinesen 1980; Veron and Pichon 1980; Hoeksema 1989; Veron 2000; Ditlev 2003). The classification of the Fungiidae was adapted according to a recent phylogenetic construction of this family (Gittenberger et al. 2011). Photographs of each species encountered were taken and, when in situ identification was not possible, specimens were collected for further examination. Collected specimens were deposited in the Borneo Marine Research Institute reference collection in Universiti Malaysia Sabah (UMS) in Kota Kinabalu. The species list was then compared to those of previous studies.
Data analysis

Data on the presence/absence of coral species per site surveyed were used for species richness analyses. For the coral families Agariciidae and Euphylliidae, data were collected at 59 sites, and for the Fungiidae at all 63 sites. The species richness estimators were calculated using the EstimateS 8.0 computer software (Colwell 2009), in which the sample order is randomised and the values are averaged. The mean and standard deviation of species richness at each sample number are calculated and the curves are extrapolated to estimate the total species richness in an area. The species accumulation curves show the rate at which additional species are found and more sampling will uncover more species, making the accumulation curves arch upwards (Magurran 2004). When the curves flatten out and reach an asymptote with minimal standard deviation, additional species are unlikely to be discovered. Indicators based on incidence (presence/absence) data are Chao 2, ICE, S Obs and Unique values (Colwell 2009).

Multivariate analyses of the coral species composition were conducted for 59 sites (where data were collected for all families) using the Plymouth Routines in Multivariate Ecological Research (PRIMER) v.6 software (Clarke and Warwick 2001; Clarke and Gorley 2006). A resemblance matrix based on the Bray-Curtis similarity measure was used to determine the similarity between sites. The BrayCurtis similarity index is equivalent to the Sorenson similarity index when used on presence/absence data (Clarke and Gorley 2006). A group-averaged hierarchical clustering dendogram and multi-dimensional scaling (MDS) plots were generated from the Bray-Curtis resemblance matrix to show the grouping of sites based on the species composition. Similarity profiles (SIMPROF) were derived from the 


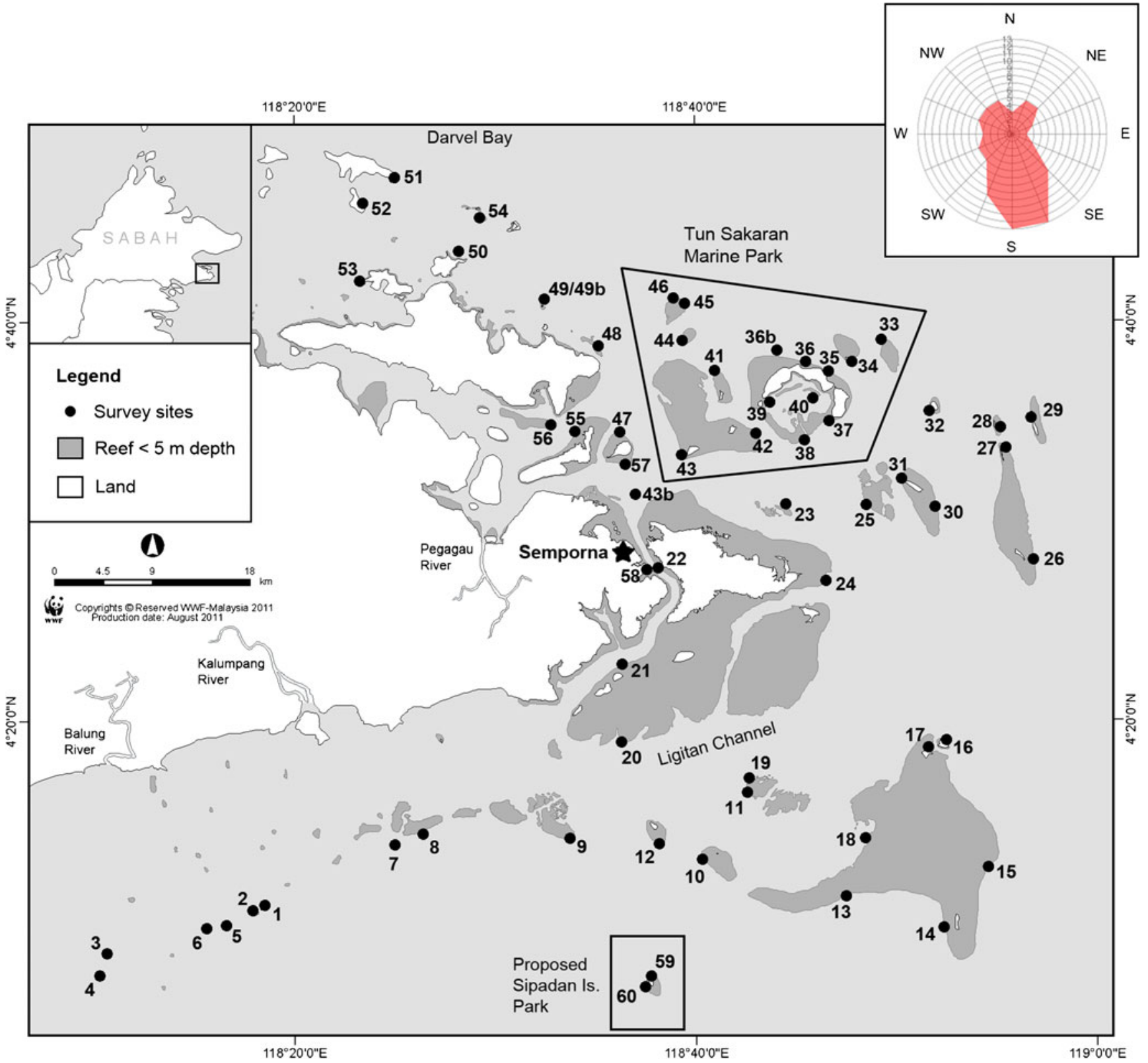

Fig. 1 The research area showing the 63 sampling sites with average wind distribution values from various directions year-round in 2011. The park boundaries are approximate. Dominant wind direction is from the S and SSE. Average wind speed is given in knots. Statistics are based on observations taken from the Tawau Airport between December 2010 and December 2011 from (Cwindfinder.com dendogram and contours were applied to the MDS plots to show significant groupings of the sites. These groupings were then illustrated on the map to highlight the species richness and distribution patterns. The analysis of similarities (ANOSIM) was employed to test for differences among the a priori group classified by reef type based on proximity to shore and wind exposure (Table 1). Similarity percentages (SIMPER) analysis was attempted to determine whether characteristic species of each group, and species that contributed most to the dissimilarities among the groups could be discerned from presence/absence data.

\section{Results}

A total of 44 species of mushroom corals were recorded from 63 sites, whereas 31 species of agariciids and 15 species of euphylliids were documented from 59 sites (Online Resource 1). Twelve species represent new records for Sabah: Cantharellus jebbi, Cycloseris distorta, C. curvata, C. hexagonalis, Cycloseris spec., Lithophyllon spinifer, the recently described Sandalolitha boucheti (see Hoeksema 2012b), Halomitra clavator, Podabacia sinai, Leptoseris amitoriensis, Pavona danai and P. duerdeni. 
Seven Agariciidae, 2 Euphylliidae and 15 Fungiidae have been added as new records for Semporna and Darvel Bay (Fig. 2; Online Resource 2). Species richness estimators were applied to compare the observed and expected species richness. The species accumulation curves show that the estimated species numbers (ICE, Chao 2) for mushroom corals reached the observed species number very closely with an error of less than one. According to this model, additional sampling could reveal one more species (Fig. 3a). The species accumulation curves for agariciid and euphyliid corals show that the estimated species numbers (ICE, Chao 2) reached the observed species number asymptotically, therefore sampling effort has been sufficient and additional sampling would not have resulted in more species (Fig. 3b, c).

Coral species composition of the sites varied with reef type, predominant wind direction and distance offshore. The number of species per site ranged from 24 at Ligitan Is. reef on the easternmost site of the barrier reef (site 15) to 55 at Batik Kulambu Is. in Darvel Bay (site 53). Species that were found at all sites are the mushroom corals Herpolitha limax, Lithophyllon repanda, Pleuractis granulosa, and Podabacia crustacea. Other coral species represented in at least $75 \%$ of the sites $(n \geq 45)$ were 12 Fungiidae (Cycloseris costulata, Ctenactis echinata, C. crassa, Danafungia horrida, D. scruposa, Fungia fungites, Heliofungia actiniformis, Lithophyllon concinna, Pleuractis gravis, P. moluccensis, P. paumotensis, and Sandalolitha robusta), 3 Agariciidae (Leptoseris scabra, Pachyseris speciosa and Pavona varians), and 3 Euphylliidae (Euphyllia glabrescens, Physogyra lichtensteini, and Plerogyra sinuosa).

Species that were encountered at only a few sites $(n \leq 3)$ appear to be limited to a certain environment based on the reef type, such as the mushroom corals Cycloseris cyclolites, $C$. distorta, C. hexagonalis, C. vaughani, Podabacia sinai, Sandalolitha boucheti, and the agariciids Leptoseris amitoriensis,
L. solida and Pavona minuta. Some rare coral species only known from a few localities in the Coral Triangle are the mushroom corals Lithophyllon ranjithi (see Ditlev 2003; Hoeksema 2004) and Halomitra clavator (see Hoeksema 2004; Hoeksema and Gittenberger 2010), whereas some species only recorded from Semporna and Darvel Bay are the euphylliids Plerogyra diabolotus, P. multilobata and P. cauliformis (Ditlev 2003).

The dendogram (using group-averaged hierarchical clustering) based on coral species composition suggested groups that reflect reef exposure (Fig. 4a). The SIMPROF test grouped the sites into six clusters with two singleton outliers, indicative of significant differences in species assemblages. At $70 \%$ similarity, the MDS ordination showed two main groups, representing the exposed and sheltered reef sites plus two smaller clusters of exposed sites (Fig. 4b). The two main groups reflect sites exposed to different wind directions, but because the predominant wind direction is from the S-SE, the southern sites are referred to as the exposed reefs and the northern sites as the relatively sheltered reefs. When the clusters were plotted on the map, there appeared to be a clear distinction between the sites in the south and east of Semporna, and the nearshore sites in the north and inner bay. Sites that had the highest species diversity $(n>50)$ were found at the sheltered nearshore reefs (Fig. 5). However, in contrast, all pairwise comparisons among the a priori groups were not statistically significant in terms of coral species composition for proximity to shore (ANOSIM Global $R=0.209, p=0.1$ ), and exposure to wind (Global $R=0.282, p=0.1$ ). There was also no significant difference in composition structure between proximity to shore and exposure to wind using the two-way crossed ANOSIM test.

Based on the SIMPER analysis, the average dissimilarity was highest between the groups South Exposed and the three sheltered areas, i.e. North Sheltered (46\%), Inner
Fig. 2 Number of species of hard coral families Fungiidae, Agariciidae and Euphylliidae (from the largest to the smallest family) documented from Semporna and Darvel Bay. Note that the sampling intensity was not consistent in all these studies

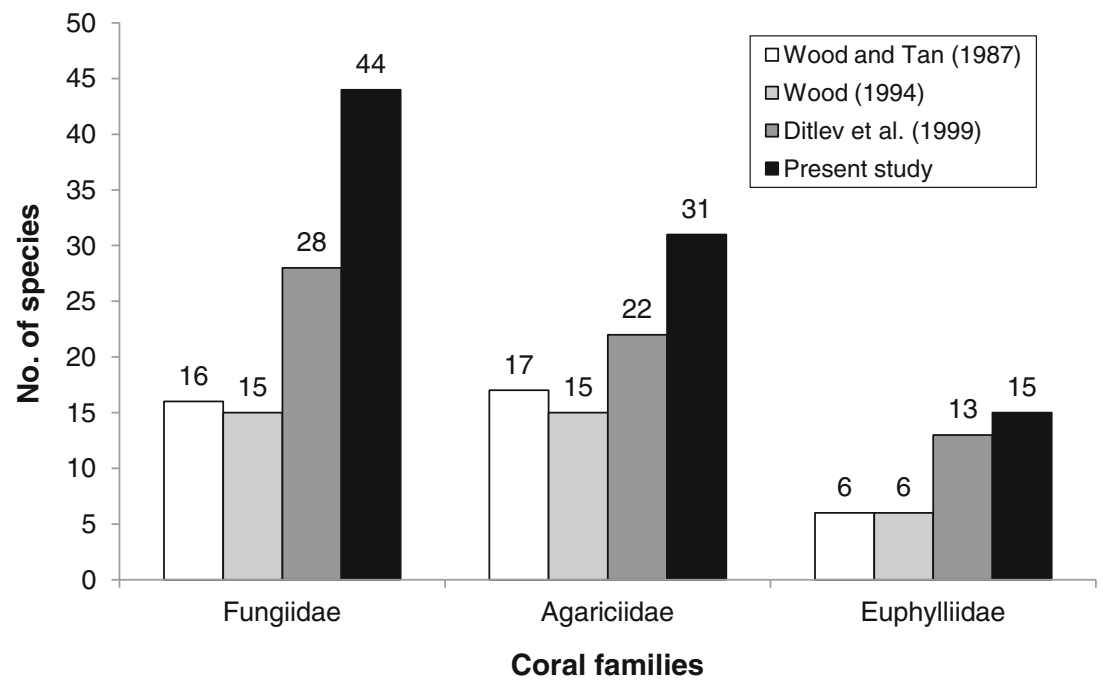



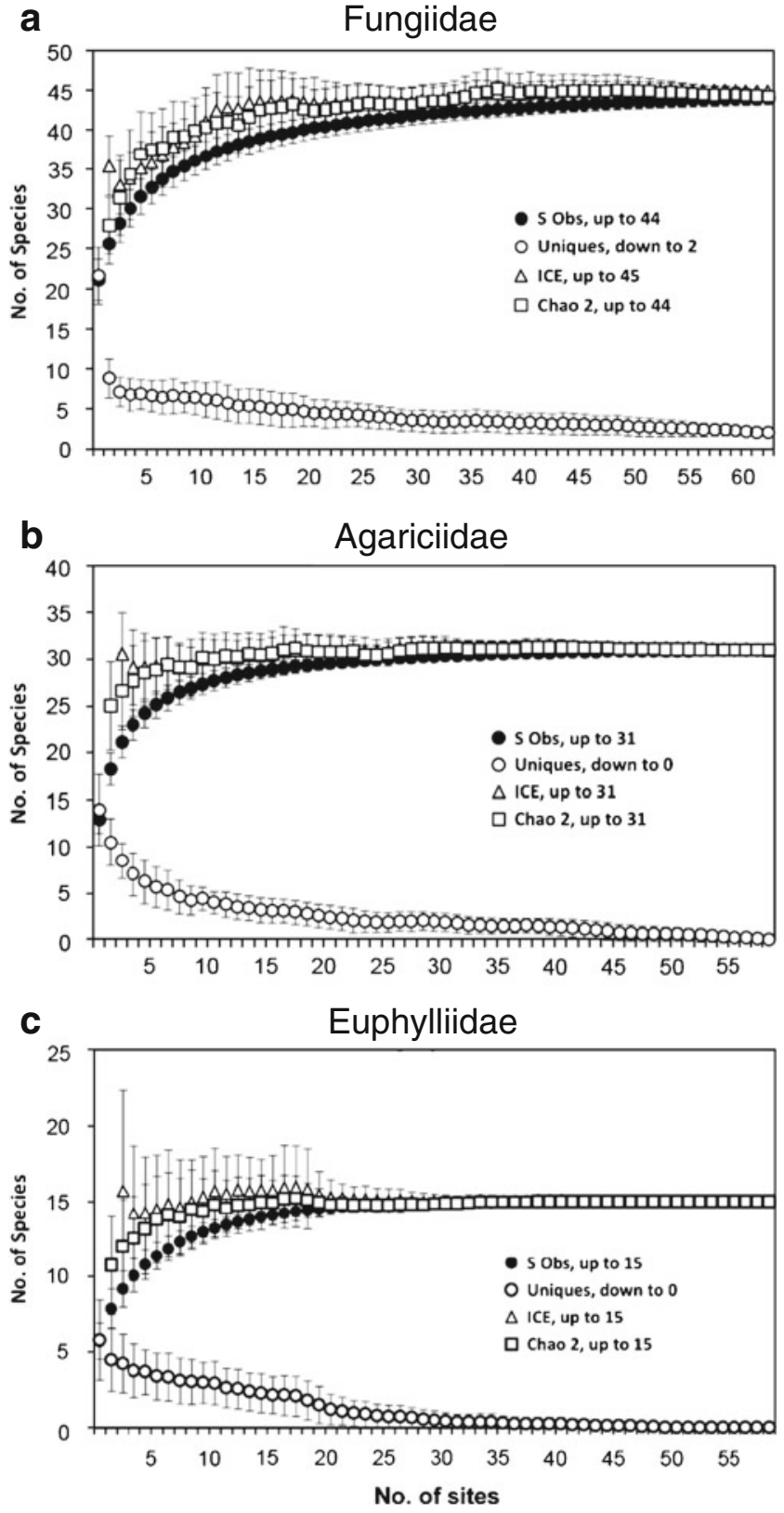

Fig. 3 Species accumulation curves for coral families a Fungiidae from 63 sites, b Agariciidae from 59 sites, and c Euphylliidae from 59 sites in Semporna. The curves appear to reach asymptotes, indicating that sampling efforts have been sufficient with the exception of the Fungiidae where the occurrence of one additional species is possible

Bay (46\%) and North (44\%) (Table 2). The groups that were most similar are North and North Sheltered $(26 \%)$, followed by North Sheltered and Inner Bay (27\%) and North and Inner Bay $(27 \%)$. The latter three groups also showed the most similar species composition within the sites of its cluster. Because only presence/absence data were used to generate the results, each species contribution was very small, which resulted in a combination of too many species being characteristic of each group. As a result, it was difficult to ascertain the species that were indicators for the groups. Hence, the individual species distributions were compared in order to distinguish potential characteristic species.

The multivariate analysis identified two main groups based on reef exposure and this was supported by the distribution patterns of certain coral species: some were found in exposed reefs, i.e. Lobactis scutaria, Pleuractis taiwanensis, Cycloseris somervillei, Pavona duerdeni and Leptoseris incrustans (Fig. 6), while some others were found exclusively in sheltered nearshore reefs such as Lithophyllon ranjithi, L. spinifer, Halomitra clavator, Leptoseris gardineri, Pavona frondifera, Nemenzophyllia turbida, Euphyllia paradivisa, Plerogyra diabolotus and P. cauliformis (Fig. 7). The coral families Fungiidae and Agarciidae had species representatives for both distribution patterns. Four euphyllid species showed a preference for nearshore reefs, whereas the others were widely distributed. Plerogyra simplex was the only euphylliid found primarily in exposed conditions, although it was also present in the Bodgaya lagoon (site 39).

\section{Discussion}

The combined number of scleractinian coral species for Semporna and Darvel Bay from the families Fungiidae, Agariciidae and Euphylliidae totals 90 species. This is approximately $17 \%$ of the overall predicted coral diversity for this region, which is expected to be between 540 and 550 species (Burke et al. 2002; Veron et al. 2009). When compared with previous studies (Wood 1987, 1994; Ditlev et al. 1999), the present study adds 24 new records to this area, 12 of which are new for the whole of Sabah. The reasons that previous studies documented fewer species may be threefold: (1) the sheer number of scleractian species $(>500)$ makes identification difficult as the focus is too broad, (2) those studies were carried out to determine the condition of the reefs rather than concentrate solely on the coral species numbers, and (3) the sampling effort of those studies did not cover the entire range of habitats in Semporna and Darvel Bay. For these reasons, rare and inconspicuous species found in a limited locality range risk being overlooked.

The mushroom coral family is one of the taxonomically best-resolved scleractinian families with a phylogenetic analysis to support the classification (Gittenberger et al. 2011). In a recent study, Psammocora explanulata and Coscinarae wellsi from the Siderastreidae have shown strong affinities with the Fungiidae (Benzoni et al. 2007, 2012). These species were not included in the data collection because they were not yet formally recognised as fungiids during the fieldwork.

With regards to the Agariciidae, specimens of Leptoseris hawaiiensis and L. scabra that were encountered during the 
Fig. 4 a Dendogram showing the group-averaged hierarchical clustering of 59 sites based on the species composition (presence/absence) of hard corals in Semporna. Significant clusters derived by SIMPROF are indicated by the solid black line. b Ordination of 59 sites in Semporna using multidimensional scaling (MDS) plots based on the significant clusters from $4 \mathrm{a}$. The solid symbols represent exposed reef sites, while the open symbols denote sheltered reef sites
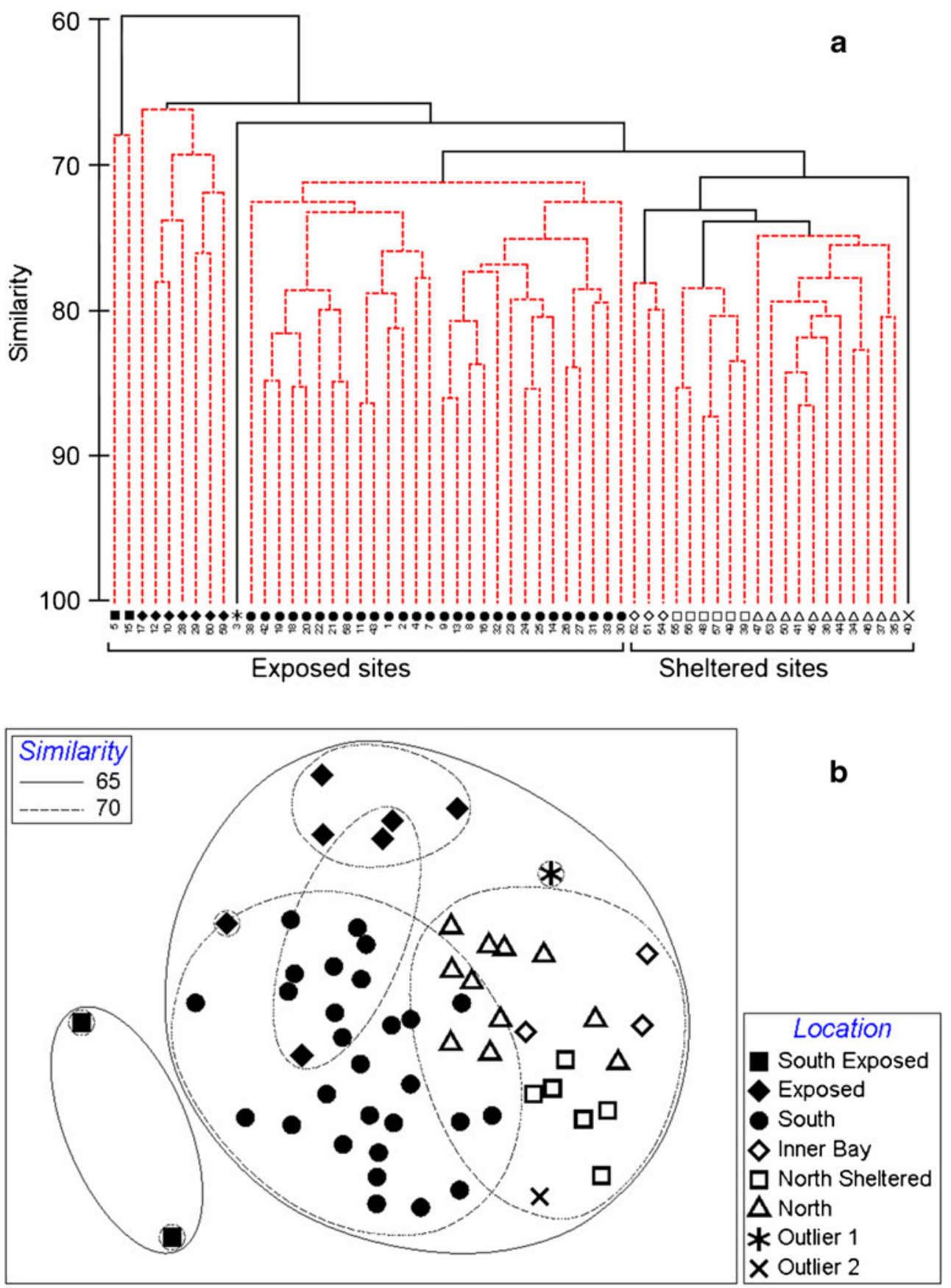

sampling appeared larger in size and had larger corallites and coarser septocoastae than the type specimens of these species (Vaughan 1907). This variation could be related to the different locality, habitat type or depth range. Specimens of L. fragilis in the present study were identified by using the original species description by Milne-Edwards and Haime (1849) and an illustration of the type (Rousseau 1854). Similar specimens at the reference collection of the Borneo Marine Research Institute were identified by Ditlev et al. (1999). Leptoseris fragilis has not been given consideration in recent Leptoseris taxonomic revisions (Dinesen 1980; Veron and Pichon 1980) because the type specimen has been misplaced. Ditlev et al. (1999) recognised an additional species from Darvel Bay, i.e. Pavona foliata, which appears to be a nomen nudum. Since they did not provide descriptions or illustrations of this Pavona coral, its identity remains doubtful. He also reported on the presence of $P$. divaricata (Lamarck, 1816), which we did not recognise during the sampling. This species resembles $P$. danai or $P$. frondifera, depending on the reef environment. There are also some uncertainties regarding the status of some Euphylliidae such as the difficulty of recognising Nemenzophyllia turbida from Plerogyra discus. Both species have identical polyps and can only be distinguished by 


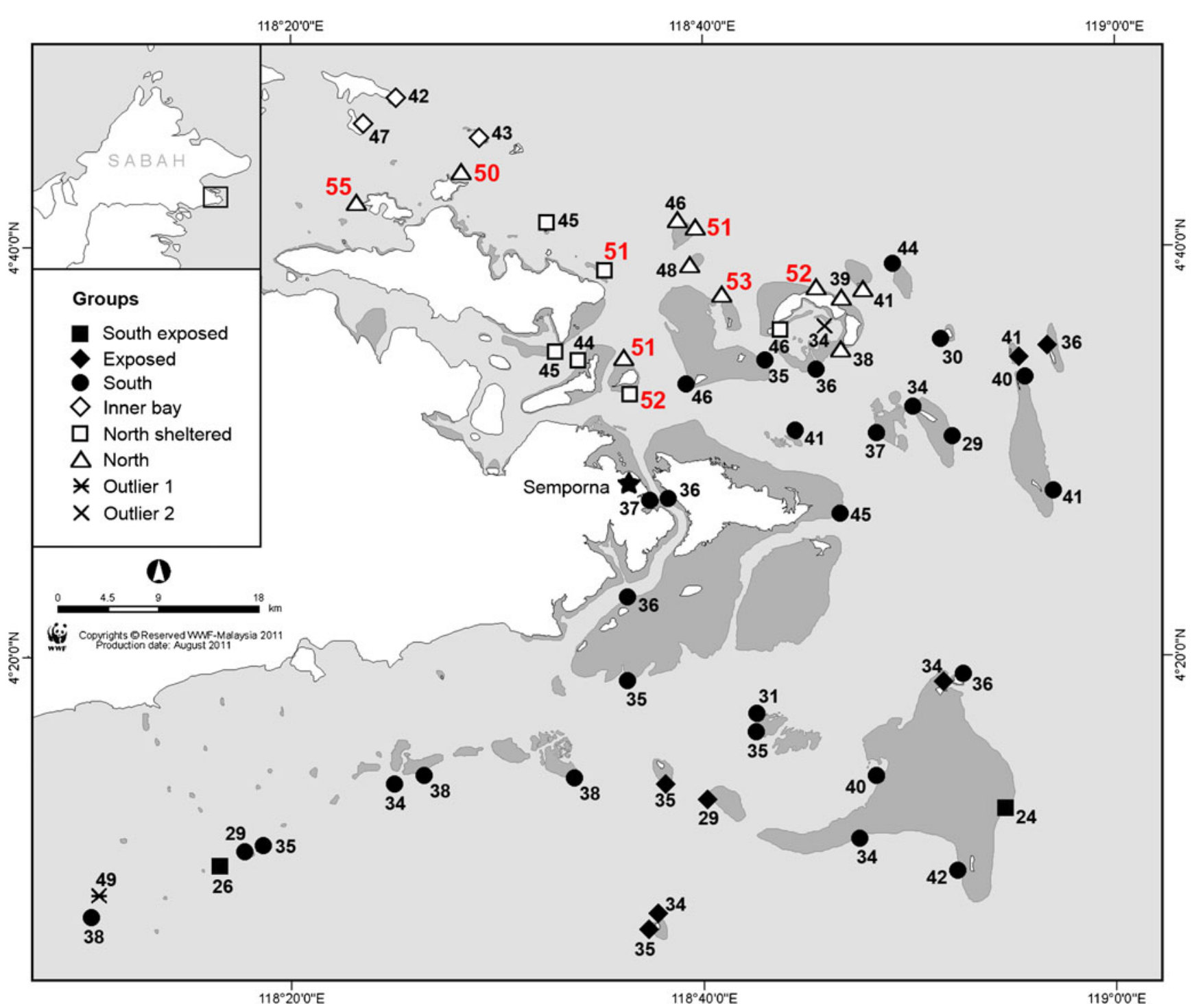

Fig. 5 Species richness patterns of the significant clusters from Fig. 4a. The numbers represent the combined species diversity of hard coral families Fungiidae, Agariciidae and Euphylliidae. Highlighted in a red, larger font are sites with the highest species richness ( $\geq 50$ species)

examining skeletal characters. During the present survey, only N. turbida was encountered.

Table 2 Results of SIMPER analysis showing the percentages of similarities for each group and dissimilarities between groups based on coral species composition

${ }^{\mathrm{a}}$ The number of characteristic and distinguishing species were truncated when the cumulative contributions was $\geq 90 \%$
The cluster analysis and MDS ordination (Fig. 4a, b) indicate that the species composition differ between the

\begin{tabular}{|c|c|c|c|c|c|c|}
\hline Groups & $\begin{array}{l}\text { South } \\
\text { Exposed }\end{array}$ & Exposed & South & $\begin{array}{l}\text { Inner } \\
\text { Bay }\end{array}$ & $\begin{array}{l}\text { North } \\
\text { Sheltered }\end{array}$ & North \\
\hline Number of sites & 2 & 7 & 28 & 3 & 6 & 11 \\
\hline Similarity (\%) within group & 68 & 70 & 74 & 79 & 80 & 78 \\
\hline Number of characteristic species ${ }^{a}$ & 16 & 31 & 33 & 34 & 39 & 39 \\
\hline \multicolumn{7}{|c|}{ Dissimilarity (\%) between groups (number of distinguishing species) ${ }^{\mathrm{a}}$} \\
\hline South exposed & - & $38(40)$ & $38(43)$ & $46(43)$ & $46(45)$ & $44(49)$ \\
\hline Exposed & & - & $33(50)$ & $38(50)$ & $38(52)$ & $32(55)$ \\
\hline South & & & - & $34(50)$ & $32(51)$ & $29(55)$ \\
\hline Inner Bay & & & & - & $27(40)$ & $27(43)$ \\
\hline North sheltered & & & & & - & $26(48)$ \\
\hline
\end{tabular}




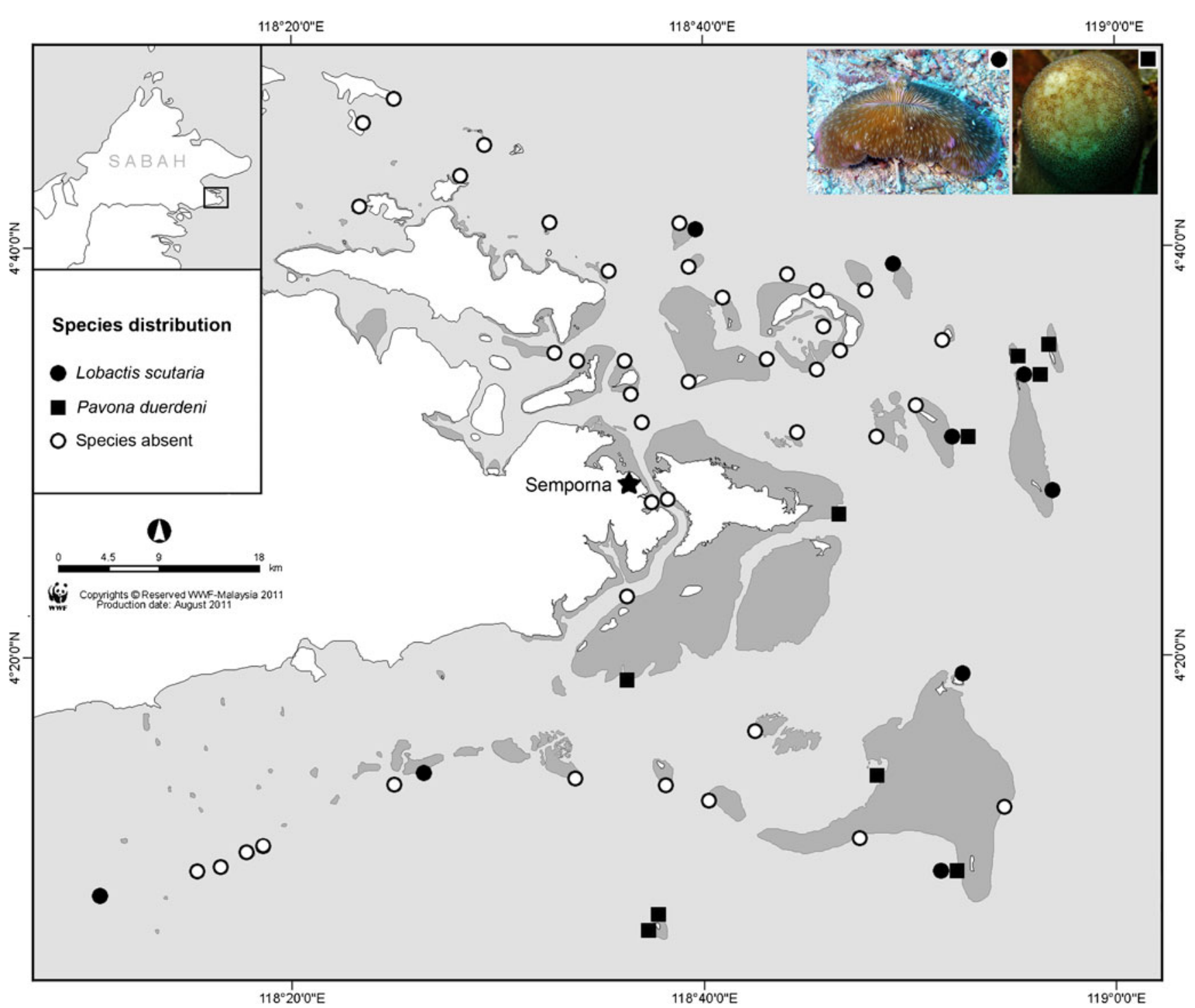

Fig. 6 Distribution patterns of some coral species with preference for exposed reefs

exposed and sheltered reef sites. The first split of $60 \%$ separates sites 5 and 15 of the barrier reef from the main cluster. Both reef sites had the lowest species numbers among all the sites and were damaged from blast fishing or other factors such as storm surge, leaving some extensive rubble fields (Affendi et al. 2012). In addition to their low species diversity, this group is composed of only two sites, indicative of the small species contributions to its group pool, in contrast to the rest of the groups. The split differentiating the exposed and sheltered groups occurred at $70 \%$ suggesting that the reefs are not very dissimilar. Because of this, the SIMPER analysis showed that some indicator species were shared among the groups, especially those from the sheltered sites, which had 78-80 \% similar coral composition within its groups. Nevertheless, when the species distribution of each coral species was determined, several species exhibited distinct distribution patterns that corresponded with preferences for specific habitat type, which could indicate potential indicator species.

There was an increase in species diversity from the exposed barrier reefs in the south to the relatively sheltered nearshore reefs in the north of Semporna and Darvel Bay. The barrier reef sites are characterised by deeper reefs that are exposed to the predominant wind direction from the SSE. These conditions, as with oceanic islands that are distant from the coast, lack gentle reef slopes or variation in exposure to wave action that otherwise may contribute to habitat heterogeneity, hence, species diversity (Hoeksema 2007, 2012a). Wave-generating winds form one of the main factors influencing the geomorphology and coral species composition of coral reefs (Umbgrove 1929; Bradbury and Young 1981; Dollar 1982; Brown et al. 1983; Moll 1983; Hoeksema 2012a). Wave action is important for modeling the coral assemblage of the exposed upper reef slopes, while 


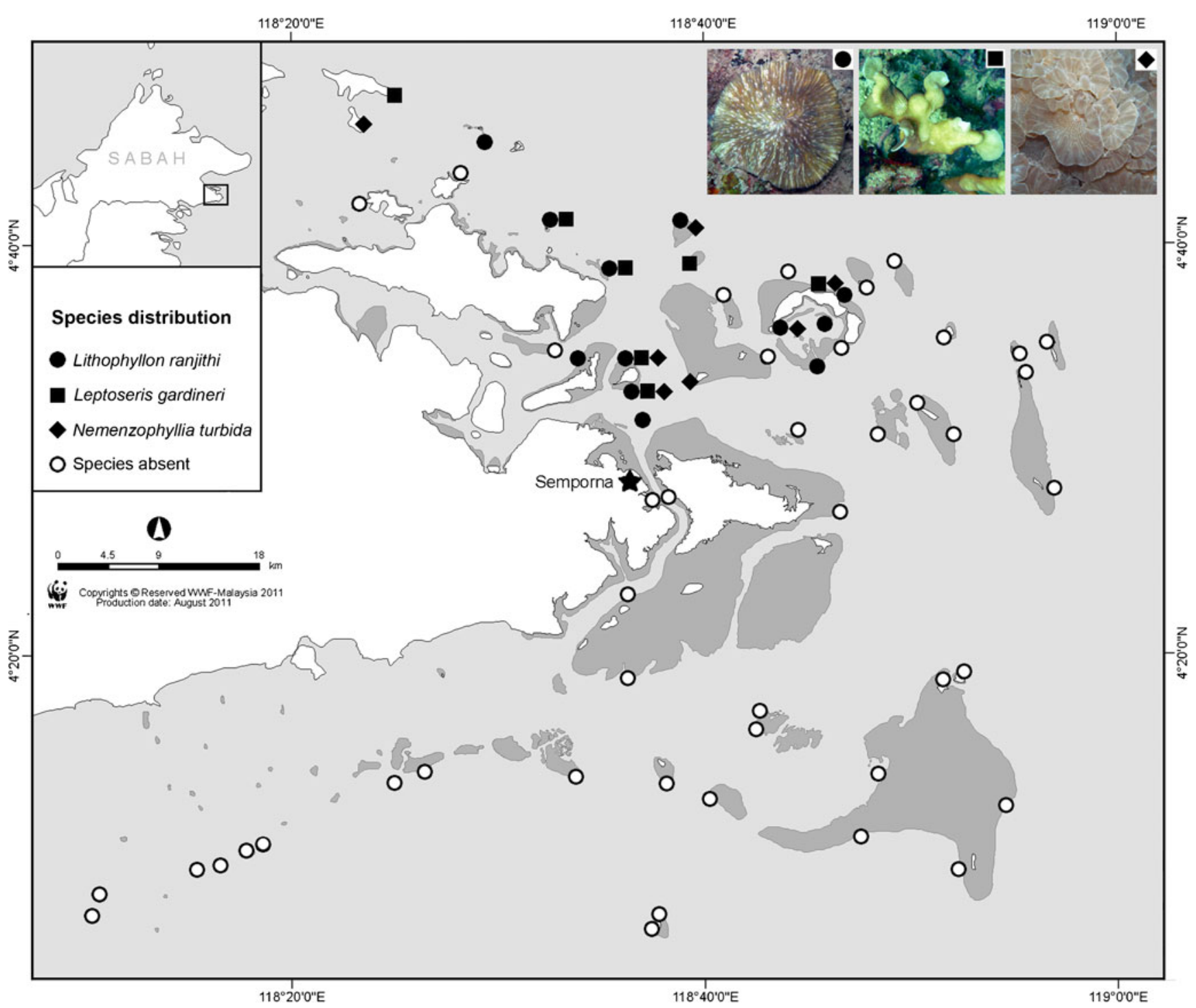

Fig. 7 Distribution patterns of some coral species with preference for nearshore northern reefs

sediment movement is the controlling factor on the lower slopes and reef base (Sheppard 1982). Corals that thrive here usually belong to species that require clear waters that are able to withstand high wave energy. For example, the mushroom corals Lobactis scutaria, Zoopilus echinatus, Pleuractis taiwanensis and Cycloseris somervillei were primarily found in the exposed outer reefs. While the former two are also common offshore species in other areas (Hoeksema et al. 2004; Hoeksema 2012a), the latter two species are usually associated with deeper and more sheltered parts of exposed reef slopes (Hoeksema and Dai 1991; Hoeksema 2010; 2012a). The agariciids Pavona duerdeni and Leptoseris incrustans were only encountered in the exposed outer reefs. Pavona duerdeni has a massive growth form and is usually found on the mid-slope, while L. incrustans is an encrusting-type of coral and can be found along mid-slopes and shallower environments. Leptoseris corals have been reported to thrive at depths that are beyond the regular range of zooxanthellate corals (Kahng and Maragos 2006; Rooney et al. 2010; Dinesen et al. 2012). Some Leptoseris species have a preference for deep water or shady conditions such as crevices, caves and overhangs (Dinesen 1980; Hoeksema et al. 2010; Hoeksema 2012c), which are some of the features of the exposed reefs. So, although the exposed reef sites may not have very high coral diversity, there are species that may preferentially be found under these reef conditions.

Highest coral species diversity is usually found in midshelf reefs (Done 1982, 1983; Moll 1983; DeVantier et al. 2006; Hoeksema 2012a). As for Semporna and Darvel Bay, there appears to be no clear mid-shelf zone, which was similar for Madang (Hoeksema 1993). Here, the reef setting is around a peninsula and due to this, there is no clear pattern in species diversity from nearhore to offshore reefs. 
Instead, the pattern in species composition and diversity appeared to be driven by the exposure to wind frequencies. The highest diversity was found in the sheltered nearshore reefs as was reported for the reefs at the Flores Sea (Hoeksema and Moka 1989). A similar pattern was also observed in gall crabs (Brachyura: Cryptochiridae), whereby higher species richness of these obligate associates were found at sites with a higher number of host species in the sheltered northern reefs, and low occurrence sites were only found in the exposed southern reefs (Van der Meij and Hoeksema in press). Although the northern nearshore reefs were dubbed as sheltered reefs, they are also influenced by the northeast winds. These reefs had visibly more habitat heterogeneity as compared to the exposed reefs. Reefs at Tun Sakaran Marine Park had clear waters with little influence from sediments, except within the Bodgaya lagoon area, while the reefs towards the inner part of Darvel Bay had reduced water clarity with horizontal visibility of approximately $2-3 \mathrm{~m}$ at some reef sites. Under this turbid environment, Ditlev et al. (1999) reported that some fungiid corals in the outer shoals of the bay reach enormous dimensions and form dense populations, although he did not specify their names. He also stated that Leptoseris and euphylliid corals were mostly found along the lower reef slopes of the bay. The present sampling sites only extended to the outer part of the bay, with Tabawan Is. at the northernmost site. Mushroom corals that were found at the nearshore reefs are Halomitra clavator Lithophyllon ranjithi, L. spinifer and Heliofungia fralinae. Halomitra clavator was confined to the northernmost sites of the bay that were facing the open sea while the latter three species had a larger distribution that extended to the reefs within the park. Although these species are associated with sheltered reefs, they, except for L. ranjithi, have a preference for deep reefs with clear waters (Hoeksema 2012a). Lithophyllon spinifer has also been found on soft bottom substrates (Claereboudt and Hoeksema 1987; Hoeksema 1993, 2012a).

Agariciid and euphylliid corals have not been as well studied as the fungiid coral family in terms of species distribution and richness patterns on a local scale. For agariciid coral, Leptoseris gardineri and Pavona frondifera were the only two species that exhibited a preference for sheltered reef conditions. Both species have foliose growth forms, but $L$. gardineri is usually found on the reef slope while $P$. frondifera is usually encountered in shallow reef parts. Euphylliid corals only found at sheltered sites are Nemenzophyllia turbida, Euphyllia paradivisa, Plerogyra diabolotus and Plerogyra cauliformis. Ditlev (2003) collected specimens of $P$. diabolotus and P. cauliformis from Mabul Is. (site 10). So, although in the present study these species were only observed at sheltered sites, they may also be found on the barrier reef, which was observed for P. multilobata (sites 18 and 19). Nemenzophyllia turbida is known to prefer turbid conditions. This species was first discovered on a reef with extremely high levels of suspended sediment, but with good water circulation at $15 \mathrm{~m}$ depth (Hodgson and Ross 1981). In the present study, $N$. turbida was found on the mid- and lower reefs slopes with sheltered conditions. Not much is known about E. paradivisa except that it is commonly found at shallow reef environments protected from strong waves (Veron 2000). The holotype was collected from $8 \mathrm{~m}$ depth at Bolinao, Philippines (Veron 1990).

Low species diversity at a few exposed sites may also result from blast fishing, as previously observed on the reefs of Si Amil Is. and Ligitan Is., with only 27 and $18.7 \%$ live coral cover, respectively (Pilcher and Cabanban 2000). Both islands are situated furthest from the coast, making law enforcement difficult. According to Pilcher and Oakley (1997), an average of four blasts were recorded every hour around the reefs of Mabul and Ligitan. In the present study, damage at Ligitan Is. (Site 15) is reflected by the lowest coral species diversity $(n=24)$ with live coral cover between 8 and $15 \%$ over a very large area (Affendi et al. 2012). Several explosions were heard during dives (personal observations), and in addition to the reefs mentioned above, other sites appeared damaged by previous blasts including the reefs of the Tun Sakaran Marine Park (Wood 2006a). There is no evidence that blast fishing is more rampant at the exposed sites than the sheltered sites, except what can be inferred from the rubble fields at greater depths and the reef status data from Affendi et al. (2012). Regular monitoring is only carried out at reefs within the park area, and a phase shift from hard coral to soft coral cover has been reported for blasted reefs in the park (Wood and Dipper 2008).

Despite the above, the coral species diversity of Semporna and Darvel Bay is still remarkably high. The total of 44 species of mushroom corals that have been recorded from the present study surpasses other areas with very high biodiversity in the Coral Triangle that have been studied (Hoeksema et al. 2004; Hoeksema 2007, 2008). To date, Semporna holds the record for the highest species diversity of this coral family. There were also species that are endemic to northeastern Borneo, such as the fungiid Lithophyllon ranjithi and the euphylliids Plerogyra multilobata, P. diabolotus and $P$. cauliformis that have so far not been found elsewhere in the region. The fact that reefs in the research area were $70 \%$ similar in terms of species composition indicated that the whole area is generally species-rich, with only slight variations in species diversity among the sites that corresponded to the different habitat types of the exposed and sheltered reefs.

Investigations on the coral fauna of Semporna and Darvel Bay only began in the last 50 years and much remains to be discovered about the reefs in this area. Several studies have demonstrated the importance of determining changes in coral communities by using long-term monitoring data (Brown et al. 2002; Somerfield et al. 2008), or historical data as baselines for comparison (Hoeksema and Koh 2009; 
Van der Meij et al. 2010; Hoeksema et al. 2011; Van der Meij and Visser 2011). While it is important to focus on the immediate impact or disturbances on coral reefs, such as blast fishing in the case of Semporna and Darvel Bay, it is also imperative to detect the first signs of stress on the reef, or predict the response of the reef communities to disturbance. This would enable a better understanding of the processes involved in influencing changes on the reef communities (Hughes and Connell 1999).

Acknowledgments This publication is a result of the Semporna Marine Ecological Expedition 2010 (SMEE 2010), co-organised by WWF-Malaysia, Universiti Malaysia Sabah and Universiti Malaya and Naturalis Biodiversity Center, the Netherlands. The expedition was funded through WWF-Malaysia. Research permission was granted by Sabah Parks, Department of Fisheries Sabah, and the Economic Planning Unit, Malaysia. Thanks are due to the crew of the Celebes Explorer for overseeing the logistics during SMEE 2010, Ms. Nina Ho who was invaluable to the expedition, and Mr. Sikula Magupin for producing maps of the research area. We also thank Dr. Elizabeth Wood and two anonymous reviewers for their helpful comments and suggestions.

Open Access This article is distributed under the terms of the Creative Commons Attribution License which permits any use, distribution, and reproduction in any medium, provided the original author(s) and the source are credited.

\section{References}

Affendi YA, Ho N, Kee Alfian AA, Aazani M, Muhammad Ali SH, Nara A, Munirah SS (2012) Reef status. In: Kassem KR, Hoeksema BW, Affendi YA (eds) Semporna marine ecological expedition. WWF-Malaysia, NCB Naturalis, Universiti Malaysia Sabah, Kota Kinabalu, pp 118-262

Aw SL (2009) Impact of tourism development and proposed management plan for Mabul Island, Sabah, Malaysia. MSc thesis, Universiti Malaysia Sabah

Becking LE, Cleary DFR, de Voogd NJ, Renema W, de Beer M, van Soest RWM, Hoeksema BW (2006) Beta diversity of tropical marine assemblages in the Spermonde Archipelago, Indonesia. Mar Ecol 27:76-88

Benzoni F, Stefani F, Stolarski J, Pichon M, Mitta G, Galli P (2007) Debating phylogenetic relationships of the scleractinian Psammocora: molecular and morphological evidences. Contrib Zool 76:35-54

Benzoni F, Arrigoni R, Stefani F, Reijnen BT, Montano S, Hoeksema BW (2012) Phylogenetic position and taxonomy of Cycloseris explanulata and C. wellsi (Scleractinia: Fungiidae): lost mushroom corals find their way home. Contrib Zool 81:125-146

Bradbury RH, Young PC (1981) The effects of a major forcing function, wave energy, on a coral reef ecosystem. Mar Ecol Prog Ser 5:229-241

Brown BE, Holley MC, Sya'rani L, Le Tissier M (1983) Coral assemblages of reef flats around Pulau Pari, Thousand Islands, Indonesia. Atoll Res Bull 281:1-17

Brown BE, Clarke KR, Warwick RM (2002) Serial patterns of biodiversity change in corals across shallow reef flats in Ko Phuket, Thailand, due to the effects of local (sedimentation) and regional (climatic) perturbations. Mar Biol 141:24-29
Burke L, Selig E, Spalding M (2002) Reefs at risk in Southeast Asia. World Resources Institute, Washington DC

Claereboudt M, Hoeksema BW (1987) Fungia (Verrillofungia) spinifer spec. nov., a new scleractinian coral (Fungiidae) from the IndoMalayan region. Zool Meded 61:303-309

Clarke KR, Gorley RN (2006) PRIMER v6: User manual/tutorial. PRIMER-E, Plymouth

Clarke KR, Warwick RM (2001) Change in marine communities: An approach to statistical analysis and interpretation, 2nd edn. PRIMER-E, Plymouth

Cleary DFR, Becking LE, de Voogd NJ, Renema W, de Beer M, van Soest RWM, Hoeksema BW (2005) Variation in the diversity and composition of benthic taxa as a function of distance offshore, depth and exposure in the Spermonde Archipelago, Indonesia. Estuar Coast Shelf Sci 65:557-570

Cleary DFR, Suharsono, Hoeksema BW (2006) Coral diversity across a disturbance gradient in the Pulau Seribu reef complex off Jakarta, Indonesia. Biodivers Conserv 15:3653-3674

Colwell RK (2009) EstimateS: Statistical estimation of species richness and shared species from samples. Version 8.2. User's Guide and application. http://purl.oclc.org/estimates. Accessed 23 February 2012

Cornell HV, Karlson RH (1996) Species richness of reef-building corals determined by local and regional processes. J Anim Ecol 65:233-241

De Silva MWRN, Cabanban AS, Ditlev H, Ridzwan AR (1999) Status of coral reefs of Darvel Bay. In: De Silva MWRN, Ridzwan AR, Saleem M, Cabanban AS (eds) Ekspedisi Galaxea '98. A study of living marine resources of Darvel Bay, Sabah, Malaysia. Universiti Malaysia Sabah, Malaysia

DeVantier L, De'ath G, Turak E, Done T, Fabricius K (2006) Species richness andcommunity structure of reef-building corals on the nearshore Great BarrierReef. Coral Reefs 25:329-340

Dinesen ZD (1980) A revision of the coral genus Leptoseris (Scleractinia: Fungiima: Agariciidae). Mem Qld Mus 20:181-235

Dinesen ZD, Bridge TCL, Luck DG, Kahng SE, Bongaerts (2012) Importance of the coral genus Leptoseris to mesophotic coral communities in the Indo-Pacific. Poster 12th Int Coral Reef Symp. P101. http://www.icrs2012.com/eposters/P101.pdf

Ditlev H (2003) New scleractinian corals (Cnidaria: Anthozoa) from Sabah, North Borneo. Description of one new genus and eight new species, with notes on their taxonomy and ecology. Zool Meded 77:193-219

Ditlev H, De Silva MWRN, Ridzwan AR, Toerring D, Widt S (1999) Hard corals of Darvel Bay. In: De Silva MWRN, Ridzwan AR, Saleem M, Cabanban AS (eds) Ekspedisi Galaxea'98. A study of living marine resources of Darvel Bay, Sabah, Malaysia. Universiti Malaysia Sabah, Malaysia, pp 51-71

Dollar SJ (1982) Wave stress and coral community structure in Hawaii. Coral Reefs 1:71-81

Done TJ (1982) Patterns in the distribution of coral communities across the Central Great Barrier Reef. Coral Reefs 1:95-107

Done TJ (1983) Coral zonation: Its nature and significance. In: Barnes DJ (ed) Perspectives on Coral Reefs. Clouston, Manuka, pp 107-147

Fenner D (2001) Reef corals of Banggi area reefs, Sabah, Malaysia. Pulau Banggi Project for Coral Reef Biodiversity. Greenforce: ReefBase

Fitch FH (1950) Report of the geological survey department for the year 1950. Brit Territ in Borneo. WF Chater Government Printer, Kuching Sarawak

George JD, George J (1987) Macroinvertebrates. In: The corals reefs of the Bodgaya Islands (Sabah: Malaysia) and Pulau Sipadan. Malay Nat J 40:225-260

Gittenberger A, Reijnen BT, Hoeksema BW (2011) A molecularly based phylogeny reconstruction of mushroom corals (Scleractinia: 
Fungiidae) with taxonomic consequences and evolutionary implications for life history traits. Contrib Zool 80:107-132

Harborne AD, Fenner D, Barnes A, Beger M, Harding S, Roxburgh T (2000) Status report on the coral reefs of the east coast of Peninsula Malaysia. Coral Cay Conservation Ltd., Malaysia

Ho N, Kassem KR (2009) Reef status of Semporna Priority Conservation Area. WWF-Malaysia, Kota Kinabalu

Hodgson G, Ross MA (1981) Unreported scleractinian corals from the Philippines. Proc 4th Int Coral Reef Symp 2:171-175

Hoeksema BW (1989) Taxonomy, phylogeny and biogeography of mushroom corals (Scleractinia: Fungiidae). Zool Verh 254:1-295

Hoeksema BW (1993) Mushroom corals (Scleractinia: Fungiidae) of Madang Lagoon, northern Papua New Guinea: an annotated checklist with the description of Cantharellus jebbi spec. nov. Zool Meded 67:1-19

Hoeksema BW (2004) Impact of budding on free-living corals at East Kalimantan, Indonesia. Coral Reefs 23:492

Hoeksema BW (2007) Delineation of the Indo-Malayan centre of maximum marine biodiversity: The Coral Triangle. In: Renema W (ed) Biogeography, time and place: Distributions, barriers and islands. Springer, Dordrecht, pp 117-178

Hoeksema BW (2008) Stony corals (Fungiidae). In: Hoeksema BW, Van der Meij SET (eds) Cryptic marine biota of the Raja Ampat Islands group. Progress report Ekspedisi Widya Nusantara (E-Win), pp 8-12

Hoeksema BW (2010) Stony corals. In: Hoeksema BW, van der Meij SET (eds) Crossing marine lines at Ternate: capacity building of junior scientist in Indonesia for marine biodiversity assessments. Progress report Ternate Expedition (2009), pp 19-25

Hoeksema BW (2012a) Distribution patterns of mushroom corals (Scleractinia: Fungiidae) across the Spermonde Shelf, South Sulawesi. Raffles Bull Zool 60:183-212

Hoeksema BW (2012b) Mushroom corals (Scleractinia: Fungiidae) of Espiritu Santo (Vanuatu, West Pacific) with the description of a new species. Zoosystema 34:429-443

Hoeksema BW (2012c) Forever in the dark: the cave-dwelling azooxanthellate reef coral Leptoseris troglodyta sp. n. (Scleractinia, Agariciidae). ZooKeys 228:21-37

Hoeksema BW, Dai CF (1991) Scleractinia of Taiwan. II Family Fungiidae (with the description of a new species). Bull Zool Inst 30:201-226

Hoeksema BW, Gittenberger A (2010) High densities of mushroom coral fragments at West Halmahera, Indonesia. Coral Reefs 29:691

Hoeksema BW, Koh EGL (2009) Depauperation of the mushroom coral fauna (Fungiidae) of Singapore (1860s-2006) in changing reef conditions. Raffles Bull Zool Suppl 22:91-101

Hoeksema BW, Moka W (1989) Species assemblages and ecomorph variation of mushroom corals (Scleractinia: Fungiidae) related to reef habitats in the Flores Sea. Neth J Sea Res 23:149-160

Hoeksema BW, Suharsono, Cleary DFR (2004) Stony corals. In: Hoeksema BW (ed) Marine biodiversity of the coastal area of the Berau region, East Kalimantan, Indonesia. Progress report East Kalimantan Program - Pilot phase (October 2003), pp 7-16

Hoeksema BW, Dautova TN, Savinkin OV, Tuan VS, Ben HX, Hoang PK, Du HT (2010) The westernmost record of the coral Leptoseris kalayaanensis in the South China Sea. Zool Stud 49:325

Hoeksema BW, van der Land J, van der Meij SET, van Ofwegen LP, Reijnen BT, van Soest RWM, de Voogd NJ (2011) Unforeseen importance of historical collections as baselines to determine biotic change of coral reefs: the Saba Bank case. Mar Ecol $32: 135-141$

Hughes TP, Connell JH (1999) Multiple stressors on coral reefs: a long-term perspective. Limnol Oceanogr 44:932-940

Isley J, Christopher S, Enderby S, Oldfield M, Munns R (2005) Sipadan Mabul Kapalai: Sabah's Underwater Treasure. Natural History Publications (Borneo), Kota Kinabalu
Kahng SE, Maragos JE (2006) The deepest, zooxanthellate scleractinian corals in the world? Coral Reefs 25:254

Karlson RH (1999) Dynamics of coral communities. Kluwer, Dordrecht

Karlson RH, Cornell HV (1999) Integration of local and regional perspectives on the species richness of coral assemblages. Am Zool 39:104-112

Kirk HJC (1962) The geology and mineral resources of the Semporna Peninsula, North Borneo. Geol Surv Dept, Brit Territ in Borneo. Mem 14:1-178

Magurran AE (2004) Measuring biological diversity. Blackwell, Oxford

Milne-Edwards H, Haime J (1849) Recherches sur les polypiers. Monographie des Astréides. Ann Sci Nat Zool (3)11:233-312

Moll H (1983) Zonation and diversity of Scleractinia on reefs off S.W. Sulawesi, Indonesia. PhD thesis, Leiden University, Leiden

Moll H, Suharsono (1986) Distribution, diversity and abundance of reef corals in Jakarta Bay and Kepulauan Seribu. UNESCO Rep Mar Sci 40:112-125

Morris PG (1973) Some preliminary notes on Sabah Coral Reefs. Borneo Res Bull 5:57-61

Morris PG (1977) A note on the occurrence of the Crown of Thorns starfish Acanthaster planci (L) on some Sabah coral reefs. Malay Nat J 30:79-85

Morris PG (1978) Notes on the distribution, geology and invertebrate faunas of some coral reefs in Darvel Bay, Sabah, Malaysia. Sarawak Mus J 26:211-234

Munro C (2005) Diving systems. In: Eleftheriou A, McIntyre A (eds) Methods for the study of marine benthos. Blackwell, Oxford, pp $112-159$

Pilcher N, Cabanban AS (2000) The status of coral reefs in eastern Malaysia. Global Coral Reef Monitoring Network (GCRMN) Report. Australia Institute of Marine Science, Townsville, 63 pp

Pilcher NJ, Oakley SG (1997) Unsustainable fishing practices: Crisis in coral reef ecosystems of Southeast Asia. Procs. Oceanology International 97 Pacific Rim, Singapore. Spearhead Exhibitions, Surrey, pp 77-87

Roe FW (1951) Report of the geological survey department for the year 1951. Malaya Publishing House, Sinapore, Brit Territ in Borneo

Rooney J, Donham E, Montgomery A, Spalding H, Parrish F, Boland R, Fenner D, Gove J, Vetter O (2010) Mesophotic coral ecosystems in the Hawaiian Archipelago. Coral Reefs 29:36-367

Rousseau L (1854) Zoophytes. In: Voyage au pole Sud et dans l'Océanie sur les corvettes l'Astrolabe et la Zélée sous le commandement de MJ Dumont-d'Urville. Zoologie, Paris, pp 119-124

Schmitt EF, Sluka RD, Sullivan-Sealey KM (2002) Evaluating the use of roving diver and transect surveys to assess the coral reef fish assemblage of southeastern Hispaniola. Coral Reefs 21:216-223

Sheppard CRC (1982) Coral populations on reef slopes and their major controls. Mar Ecol Prog Ser 7:83-115

Somerfield PJ, Jaap WC, Clarke KR, Callahan M, Hackett K, Porter J, Lybolt M, Tsokos C, Yanev G (2008) Changes in coral reef communities among the Florida Keys, 1996-2003. Coral Reefs 27:951-965

Toda T, Okashita T, Maekawa T, Alfian BAAK, Rajuddin MKM, Nakajima R, Chen W, Takahashi KT, Othman BHR, Terazaki M (2007) Community structures of coral reefs around Peninsular Malaysia. J Oceanogr 63:113-123

Umbgrove JHF (1929) The influence of the monsoons on the geomorphology of coral islands. Proc 4th Pac Sci Congr BataviaBandoeng (Java) 2A:49-54

Van der Meij SET, Visser RR (2011) The Acropora humilis Group (Scleractinia) of the Snellius Expedition (1929-30). Raffles Bull Zool 59:9-17

Van der Meij SET, Hoeksema BW (in press) Distribution of gall crabs inhabiting mushroom corals on Semporna reefs, Malaysia. Mar Biodiv 
Van der Meij SET, Hoeksema BW, Suharsono (2010) Long-term changes in coral assemblages under natural and anthropogenic stress in Jakarta Bay (1920-2005). Mar Pollut Bull 60:14421454

Vaughan TW (1907) Recent Madreporaria of the Hawaiian Islands and Laysan. US Natl Mus Bull 59:427

Veron JEN (1990) New scleractinia from Japan and other Indo-West Pacific countries. Galaxea 9:95-173

Veron JEN (2000) Corals of the world, volume 2. Australian Institute of Marine Science, Townsville

Veron JEN, Pichon M (1980) Scleractinia of Eastern Australia III. Families Agariciidae, Siderastreidae, Fungiidae, Oculinidae, Merulinidae, Mussidae, Pectiniidae, Caryophylliidae, Dendrophylliidae. Aust Inst Mar Sci Monogr Ser 4:1-459

Veron JEN, Devantier LM, Turak E, Green AL, Kininmonth S, Stafford-Smith M, Peterson N (2009) Delineating the coral triangle. Galaxea J Coral Reef Stud 11:91-100

Wood EM (1978) Coral reefs in Sabah: actual damage and potential dangers. Malay Nat J 31:49-57

Wood EM (1979) Ecological study of coral reefs in Sabah. Technical report, WWF Project Number MYS 15, Petaling Jaya, Malaysia

Wood CR (1987) Physical features of the islands and coral reefs. In: The corals reefs of the Bodgaya Islands (Sabah: Malaysia) and Pulau Sipadan. Malay Nat J 40:169-188

Wood CR (1994) Physical features of the Sipadan reef. In: Pulau Sipadan: Reef life and ecology. Technical report, WWF Project Number MYS 233/92, Petaling Jaya, Malaysia, pp 11-22

Wood EM (Ed) (2001) Management plan for the Semporna Islands Park, Sabah, Malaysia, proposed through the Semporna Islands
Project. Marine Conservation Society, Sabah Parks, WWFMalaysia, Nature Link

Wood EM (2006a) Report of fish blasting incident in the Tun Sakaran Marine Park, and the need for increased surveillance. Darwin Initiative, Semporna Islands Darwin Project, Marine Conservation Society

Wood EM (2006b) Sustainable use and conservation of biodiversity in the Tun Sakaran Marine Park. Action plan and proposed regulations. Sabah Parks, Darwin Initiative, Marine Conservation Society

Wood EM, Dipper F (2008) What is the future for extensive areas of reef impacted by fish blasting and coral bleaching and now dominated by soft corals? A case study from Malaysia. Proc 11th Int Coral Reef Symp 1:410-415

Wood EM, Tan BS (1987) Hard Coral. In: The corals reefs of the Bodgaya Islands (Sabah: Malaysia) and Pulau Sipadan. Malay Nat J 40:189-224

Wood CR, Wood EM (1987) Fishes. In: The corals reefs of the Bodgaya Islands (Sabah: Malaysia) and Pulau Sipadan. Malay Nat J 40:285-310

Wood EM, Dipper F, Angkaji A (2004) Patterns of change in reef communities revealed by the monitoring programme for the Semporna Island reefs, Sabah, Malaysia. Proc 10th Int Coral Reef Symp 1943-1949

Wood EM, Irwan M, Brunt H (2008) Stop fish blasting campaign: Tun Sakaran Marine Park. Semporna Islands Darwin Project, Sabah Parks, Darwin Initiative, Marine Conservation Society

Wyrtki K (1961) Physical oceanography of the Southeast Asian waters. Univ. Calif., NAGA Rept., No. 2 